\title{
Goal Content for the Practice of Physical Activity
}

Antunes, Raul Couto, N Monteiro, D Moutao, J Marinho, D A L Cid,

Sport Science School of Rio Maior-Polytechnic Institute of Santarém- ESDRMIPSantarém, Rio Maior, Portugal

*Corresponding author:Antunes, Sport Science School of Rio Maior- Polytechnic Institute of Santarém- ESDRMIPSantarém, Rio Maior, Portugal, Tel: +351 918649 901; E-mail: rantunes@esdrm.ipsantarem.pt

Received date: June 19, 2018; Accepted date: July 05, 2018; Published date: July 07, 2018

Copyright: @2018 Antunes, et al. This is an open-access article distributed under the terms of the Creative Commons Attribution License, which permits unrestricted use, distribution, and reproduction in any medium, provided the original author and source are credited.

\begin{abstract}
:
Goal content, represented by intrinsic and extrinsic goals, regulates motivation. The present study was undertaken to analyze the impact of goal content leading to physical activity in older adults (60 to 90 years), on the subjective well-being variables and to evaluate the differences between such variables according to the physical activity level practiced. Structural equation models (SEM) constituted by the principles of both regression and factorial analysis was used for analyzing the data obtained from The Goal Content for Exercise Questionnaire (GCEQ), The Positive and Negative Affect Schedule (PANAS) and The International Physical Activity Questionnaire (IPAQ-short form). A substantial positive effect of extrinsic goal content on satisfaction with life $(\beta .24)$ and negative affect ( $\beta .27)$ and a substantial positive effect of intrinsic objectives on positive affect ( $\beta .35)$ were observed. Health $(6.03 \pm 0.74)$ was the most important motive whereas social recognition $(3.77 \pm 1.36)$ was the least important one. Individuals with higher physical activity had greater positive effect and satisfaction with life and lower levels of negative affect. This study is of significance in comprehending the role of physical activity and well-being among older adults.
\end{abstract}

Keywords: Aging; Well-being; Physical activity; Goal content

\section{Introduction}

The inherent reasons for human involvement in an activity have been broadly studied. Thus, motivation has been extensively investigated in many areas of expertise, as it works as an engine toward the accomplishment of any activity. It can be defined as a psychological variable that leads an individual to the execution, orientation, maintenance or dropout of a physical activity or sport $[1,2]$. From that point of view, several theoretical models have addressed the issue of motivation; among them, the Self-Determination Theory (SDT) should be highlighted. The SDT represents a macro theory about human motivation and analyses the causes and consequences of intrinsically motivated behavior. According to Deci and Ryan, this theory propounds that an individual's motivation is mediated by the satisfaction of three basic psychological needs (autonomy, competence and relatedness), which determine behavior regulation through a motivational continuum that varies from a state of a motivation, characterized by the lack of intention to act, to a state of intrinsic motivation, characterized by the pleasure, interest, enjoyment and satisfaction that is inherent to the activity.

Furthermore, according to the SDT, the social context in which the activity takes place exerts an influence on the individuals' behavior and well-being, because all human activity is placed within a social context $[3,4]$. Following the SDT, Sebire, Standage, and Vansteenkiste suggested that goal content is the major predictor of an individual's behavior, thereby originating the goal content theory, which distinguishes intrinsic and extrinsic goals, and analyses their impact on motivation regulation and on the well-being of the individual. Pursuant to this theory, the goals pursued in performing a certain activity are differentiated in relation to their potential to satisfy basic psychological needs (autonomy, competence and relatedness), and the differentiated impact on the individual's well-being, according to their content (intrinsic or extrinsic), is shown [5].

On the one hand, as stated by Diener, Emmons, Larsen, and Griffin, subjective well-being is considered a long-term state that comprises two dimensions: emotional (affect) and cognitive (satisfaction with life) [6]. The concept of affect presents two relatively independent dimensions: positive affect, which reflects a state in which an individual feels excited, active and alert; and negative affect, which reflects a state in which an individual feels anguish and has no feelings of pleasure $[7,8]$. On the other hand, the concept of satisfaction with life is related to a cognitive judgement process, which is associated with an assessment done in each moment by an individual about the extent to which he feels satisfied with life. This judgement depends on the comparison between the actual circumstances and what the individual defines as an appropriate pattern $[6,9]$.

In a study with 410 adults $(\mathrm{M}=41.39$ e $\mathrm{SD}=11.02)$, Sebire, Standage, and Vansteenkiste concluded that the content of most intrinsic goals positively predicted cognitive, affective and behavioral adaptation to exercise. In the same study, the authors also identified the effects of most intrinsic goals on physical self-esteem and on psychological wellbeing, which were partially mediated by the satisfaction of basic psychological needs [10]. In another investigation, Sebire, Standage, and Vansteenkiste, using a sample of 101 adults $(M=38.79$ years; $\mathrm{SD}=11.5$ ), sought to analyze the predictive effect of goal content on physical activity. In this investigation, and in a preliminary analysis, correlations between intrinsic goals and physical activity behavior were not found; however, through an analysis of the mediating effect of autonomous motivation, they concluded that goal content may predict individuals' physical activity [11]

A different study carried out with 203 adult participants $(\mathrm{M}=32.57$ years; $S D=15.73$ ) based on the Self-Determination Theory, Gunnel, Crocker, Mack, Wilson, and Zumbo analyzed a model with the goal of verifying the effect that goal content has on basic psychological needs, 
subjective well-being and physical activity. Thus, through the basic psychological needs, positive indirect effects of goal content (more for intrinsic) on subjective well-being (subjective vitality) and physical activity levels were found. With respect to the model's adjustment, the authors found adjustment values that they considered suitable, taking the complexity of the model into account $\left(\chi^{2}(15)=52.54, \mathrm{CFI}=0.90\right.$; RMSEA $=0.11 ; 90 \% \mathrm{CI}=0.08-0.14$; SRMR $=0.06)[12]$.

With respect to the consequences of the practice of physical activity, substantial results have proven that the regular practice of physical exercise with moderate intensity has indisputably beneficial effects, not only at the physical health level, but also at the psychological and social levels; it may provide an important contribution to an individual's general well-being at all ages, and it may inclusively contribute to the improvement of self-perception regarding aging [1,13-15]. According to Neto, Lima, Gomes, Santos, and Tolentino, the relations between the practice of physical activity and subjective well-being are evident. In that study, which was composed of a sample of 187 adults who were 61-years-old or older, mainly females, it became evident that these people who practiced physical activity four to five times a week had higher levels of subjective well-being [16].

In a study involving 228 older adults $(M=78.2$ years $S D=5.8)$, Withall et al. verified that positive associations exist between the amount of moderate to vigorous physical activity (measured by the number of daily steps) and the perception of subjective well-being by older adults (satisfaction with life) [17]. According to Diener and Chan, there is evidence that high levels of subjective well-being contribute to improvements in the health and longevity of individuals; some indicators of subjective well-being are positively influenced by the practice of physical activity, such as, for example, positive affect and satisfaction with life perceived by older adults [18-20]. Although there is a general consensus about the positive effects of the practice of physical activity on well-being indicators in older adults, there are still some informational gaps regarding the role of motivation as an enhancer of this relationship [19].

Therefore, given the above, the main goal of the present study is to analyze the impact that the goal content that lead to the practice of physical activity in older adults may have on the variables that establish subjective well-being (satisfaction with life and positive and negative affect), as well as to analyze the differences in these variables according to the amount of physical activity practiced.

\section{Methodology}

\section{Participants}

In this study, 300 individuals $(n=300), 238$ females and 62 males, aged between 60 and 90 -years-old $(M=68.59$; $\mathrm{DP}=6.54)$, participated; all of them were participants in senior universities and nursing homes from the regions of Ribatejo and the western zone of continental Portugal, and were regular practitioners of physical activity (among the reported activities, maintenance gymnastics, aerobics, hydro gymnastics and walking were the most common).

\section{Instruments}

The Goal Content for Exercise Questionnaire (GCEQ) is constituted of 20 items, which are answered using a Likert-type scale with seven levels that vary between 1 ("totally disagree") and 7 ("totally agree"). Afterwards, the items are grouped into three intrinsic factors (health maintenance-e.g., "To improve my general health"; capacity development-e.g., "To learn and practice new exercises and/or activities"; social affiliation-e.g., "To share my practice experiences (exercise) with people who care about me") and two extrinsic factors (image-e.g., "To improve the general appearance of my body"; social recognition-e.g., "So that others have a good impression of me"), each of them having four items [5].

The Positive and Negative Affect Schedule (PANAS) is constituted of 20 items, which are answered using a Likert-type scale with five levels that vary between 1 ("nothing or very slightly") and 5 ("extremely"). Then, the items are grouped into two factors that represent the degree of positive (e.g., "interested", "strong", "excited") and negative (e.g., "perturbed", "scared", "angry") affect [8]. The Satisfaction with Life Scale (SWLS), in the Portuguese version (Neto), is constituted of 20 items, which are answered using a Likert-type scale with seven levels that vary between 1 ("totally disagree") and 7 ("totally agree"). Afterwards, the items are grouped into only one factor that presents an index of overall satisfaction with life (e.g., "My life is close to my ideal in many fields.") [6,21].

The International Physical Activity Questionnaire (IPAQ-short form) has been validated for 12 countries, including Portugal [22]. This questionnaire is formed of four questions related to specific types of physical activity, e.g., walking and moderate and vigorous activities, in terms of the frequency and duration of each specific type of activity, as well as the time spent seated per day in a week. The data obtained by the IPAQ are converted into MET-min/week (metabolic equivalent) through the calculation of the marked minutes per week in each category of activities by their specific metabolic equivalent. The physical activity level of each individual is ranked according to the IPAQ's own recommendations, which present the following physical activity categories:

Category 1 (Low): The lowest physical activity level, which corresponds to individuals who do not fulfill the criteria for categories 2 and 3 , who are considered to be inactive.

Category 2 (Moderate): Individuals who meet one of the following criteria:

(a) Three or more days of vigorous physical activity for at least 20 minutes a day.

(b) Five or more days of any combination of walking, or moderate or vigorous physical activity, which reaches a total minimum of physical activity of at least $600 \mathrm{MET}$-minutes/week.

Category 3 (High): Individuals who meet one of the following criteria:

(a) Vigorous activity for at least five days, reaching a total minimum of physical activity of 1500 MET-minutes/week.

(b) Seven or more days of any combination of walking, or moderate or vigorous activities, which reach a total minimum of physical activity of at least 3000 MET-minutes/week.

\section{Procedures}

\section{Procedures for data collection}

After making contact with the administrations of the senior universities and nursing homes to obtain signatures on the informed consent forms by the participants, all of the data were anonymously collected and analyzed, thereby assuring compliance with the 
Page 3 of 7

confidentiality principle. To provide further detail, the data were collected in a classroom context in the local functions of the senior universities, in small groups (maximum of 20 people) with duration of approximately 20 minutes.

With respect to the ethical procedures, the Ethics Commission of the $\operatorname{xxxxx}$ made a favorable judgment regarding this study, which also took into account the conduct code of the Helsinki Declaration, as well as the ethical assumptions that sustain scientific practice proposed by the APA.

\section{Procedures for the data analysis}

Structural equation models (SEM) were used, which is a multivariate technique that allows us to simultaneously examine the relations between latent constructs and measurement variables, as well as among several constructs of the model (Hair et al.). This type of analysis may be seen as a merger of two techniques: regression analysis and factorial analysis. While regression analysis (also known as path analysis) is concerned with hypothetic causal relations among the variables, factorial analysis is used to find a group of factors that explain the common variance among a group of items [23-24]. In operational terms, the SEM was constructed using AMOS 20.0 software, according to the orientations of several authors $[23,25,26]$.

The estimation method used was the maximum likelihood (ML) method, through the chi-square test $\left(\chi^{2}\right)$ with the respective degrees of freedom (df) and the significance level (p). The following quality adjustment indexes were also used: the Standardized Root Mean Square Residual (SRMR), the Comparative Fit Index (CFI), the TuckerLewis Index (TLI), the Root Mean Square Error of Approximation (RMSEA) and the respective confidence interval (90\% CI).

In the present study, the cut-off values suggested by $\mathrm{Hu}$ and Bentler were adopted: SRMR $\leq 0.08$, CFI and TLI $\geq 0.95$ and RMSEA $\leq 0.06$.
However, in the case of the incremental indexes (CFI and TLI), the cut-off values from $\mathrm{Hu}$ and Bentler should not be generalized, as it is equally advisable to consider values that are equal to or higher than 0.90 [27,28]. The theory behind the maximum likelihood (ML) estimation method assumes that the data have a normal multivariate distribution, thus making it necessary to analyze Mardia's coefficient, in which values higher than 5.0 are indicative that the data do not present a normal multivariate distribution [25,29].

Lastly, in order to study the differences at the subjective well-being level (satisfaction with life and positive and negative affect) according to the amount of physical activity (IPAQ categories), we first used the univariate techniques of localization measures and central tendency (mean) and dispersion measures (standard deviation), and posteriorly parametric techniques, namely the One-Way ANOVA test, to compare the means in more than two groups, complemented by a Tukey posthoc test. The significance level adopted to reject the null hypothesis was $\mathrm{p} \leq 0.05$. The data analysis was conducted using SPSS 20.0.

\section{Results}

With respect to Mardia's coefficient analysis, it was verified that there is a non-normal multivariate, because the obtained value of 29.39 exceeds the adopted cut-off value of 5.0 [25].Therefore, the BollenStine bootstrap was used as a protection measure for a sample of 2000, after previously verifying that there were no missing values [30].

Through a structural equations analysis, as can be observed in Table 1 , it is possible to observe that the initially hypothesized model (model 1) did not adjust to the data in a satisfactory way $\left(\chi^{2}=450.95 ; \mathrm{df}=181\right.$; $\mathrm{B}-\mathrm{S}=\mathrm{p}<0.000 ; \mathrm{SRMR}=0.099 ; \mathrm{TLI}=0.84 ; \mathrm{CFI}=0.87 ; \mathrm{RMSEA}=0.07190 \%$ CI 0.062-0.079).

\begin{tabular}{|c|c|c|c|c|c|c|c|c|}
\hline Models & $x^{2}$ & df & B-S & SRMR & TLI & CFI & RMSEA & $90 \% \mathrm{Cl}$ \\
\hline Model 1 & 450.95 & 181 & 0 & 0.099 & 0.84 & 0.87 & 0.071 & $0.062-079$ \\
\hline Model 2 & 386.18 & 179 & 0 & 0.097 & 0.88 & 0.9 & 0.062 & $0.054-071$ \\
\hline
\end{tabular}

Table 1: Adjustment indexes of tested models (impact of each factor/motive on well-being variables)

In this way, we looked for the potential fragilities of the model, through an analysis of the residual values among the items and of the modification indexes, and the model was readjusted with the correlation between the errors of the image and health factors, as well as between the errors of the social affiliation and social recognition factors. After this procedure, the final model adjusted itself to the data in a satisfactory manner $\left(\chi^{2}=386.18 ; \quad \mathrm{df}=179 ; \quad \mathrm{B}-\mathrm{S}=\mathrm{p}<0.000\right.$; SRMR $=0.097 ; \quad$ TLI $=0.88 ; \quad$ CFI $=0.90 ; \quad$ RMSEA $=0.062 \quad 90 \% \quad$ CI 0.054-0.071); however, not all of the cut-off values adopted in the methodology were reached [25].

Nonetheless, as was mentioned in the methodology section, some authors also advise the consideration of values equal to or higher than 0.90 in incremental indexes $[23,25,28]$. Although in the case of the Standardized Root Mean Square Residual (SRMR), values up to 0.10 may be considered as acceptable (Worthington et al.), thus avoiding the rejection of good models [26].
On the other hand, from an analysis of the results from the respecified model (Figure 1), it is verifiable that the goal content related to the extrinsic goal content present a significant positive effect on satisfaction with life $(\beta=0.24)$ and on negative affect $(\beta=0.27)$. Goal content related to intrinsic goal content have a significant and positive effect on positive affect $(\beta=0.35)$. In relation to the effect of goal content on physical activity, it is possible to verify that it is not significant.

Once the model only adjusted itself when the errors from health (intrinsic) and image (extrinsic) factors were correlated, as well as the errors from the social affiliation (intrinsic) and social recognition (extrinsic) factors, indicating that these factors may not be understood as different in their content (intrinsic vs. extrinsic) by the individuals in our sample, the individual contribution of each factor (goal content) to the well-being variables was analyzed. 
They were still adjusted with the cut-off values on the border between the adjusted and non-adjusted model referring to the incremental indexes, more concretely, to the TLI. It does corrections according to the model's complexity, including penalizations for free parameters that do not improve the model's adjustment. This is the reason why the majority of authors only use the CFI, which does corrections according to the sample size [31].

Regarding the adjustment of the data to the measurement models, as can be observed in Table 2, all of the measurement models adjusted themselves to the data in a satisfactory way, although not all of the cutoff values adopted in the methodology were reached in every model [27]. Nevertheless, as was mentioned in the methodology section, some authors also advise the consideration of values equal to or higher than 0.90 in incremental indexes and between $\leq 0.05$ and $\leq 0.08$ in absolute indexes, thereby avoiding the rejection of good models $[23,25,28]$.

Regarding the mean value of each motive for the practice of physical activity, it was verified that the individuals in our sample point to health as the most important motive $(6.03 \pm 0.74)$, followed by capacity development $(5.08 \pm 1.12)$, social affiliation $(4.90 \pm 1.11)$, and image $(4.89 \pm 1.12)$, while social recognition was the least important motive $(3.77 \pm 1.36)$.

The analysis of the effect that each factor (motive) has on the wellbeing variables (satisfaction with life and positive and negative affect) verifies that some significant and positive effects stand out: the effect of the health factor on satisfaction with life ( $\beta .23)$ and on positive affect $(\beta .30)$; the effect of the capacity development factor on positive affect $(\beta .30)$; the effect of the image factor on satisfaction with life ( $\beta .28)$, on positive affect ( $\beta .21)$ and on negative affect ( $\beta .18)$; and the effect of the social recognition factor on negative affect ( $\beta .24)$. On the other hand, none of the goal content had a significant effect on the amount of physical activity.

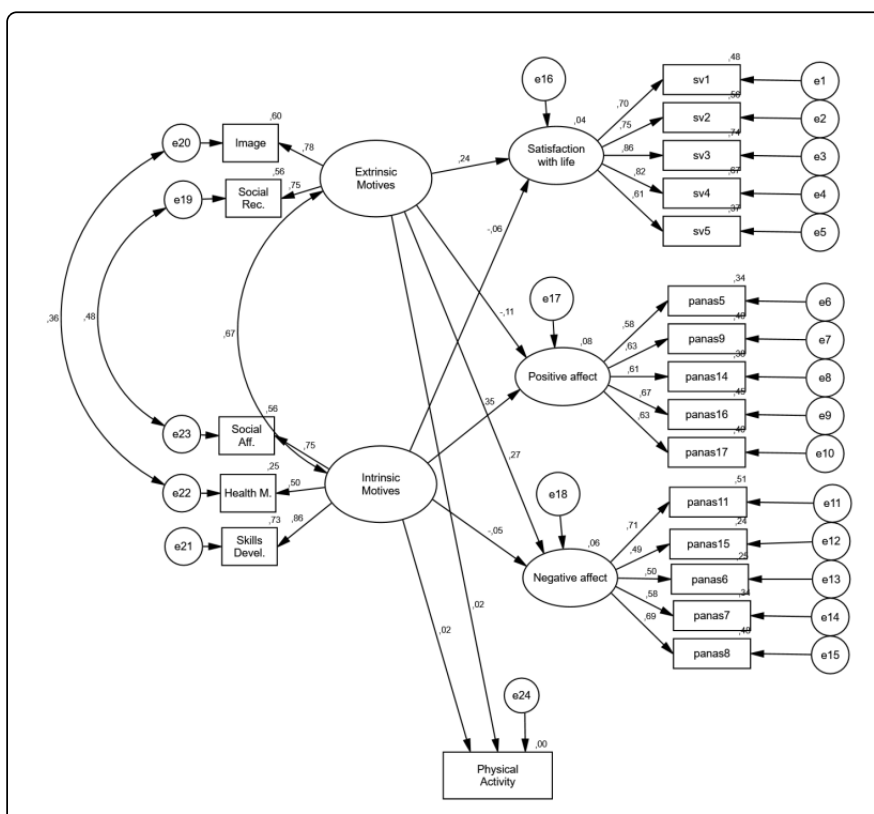

Figure 1: Standardized individual parameters in re-specified model

\begin{tabular}{|l|l|l|l|l|l|l|l|l|}
\hline Models & $\mathbf{X}^{\mathbf{2}}$ & $\mathbf{d f}$ & $\mathbf{B}-\mathbf{S}$ & $\mathbf{S R M R}$ & TLI & CFI & RMSEA & $\mathbf{9 0 \%}$ CI \\
\hline Social Aff. & 310.94 & 149 & 0 & 0.099 & 0.89 & 0.9 & 0.06 & $0.051-0.070$ \\
\hline Health & 313.89 & 167 & 0 & 0.088 & 0.91 & 0.92 & 0.054 & $0.045-0.063$ \\
\hline Capacities Dev. & 296 & 149 & 0 & 0.096 & 0.9 & 0.91 & 0.057 & $0.048-0.067$ \\
\hline Image & 298.48 & 149 & 0 & 0.096 & 0.9 & 0.91 & 0.058 & $0.048-0.067$ \\
\hline Social Rec. & 355.85 & 167 & 0 & 0.099 & 0.89 & 0.91 & 0.061 & $0.053-0.070$ \\
\hline
\end{tabular}

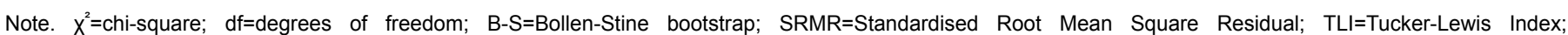
$\mathrm{CFI}=$ Comparative Fit Index; RMSEA=Root Mean Squared Error of Approximation; $90 \% \mathrm{Cl}=$ Confidence interval of the value of RMSEA.

Table 2: Adjustment indexes of tested models (impact of each factor/motive on well-being variables)

Regarding the analysis of the differences that existed at the wellbeing variables level, according to the amount of the individuals' regular practice of physical activity, as can be observed in Table 3, in a general manner, it is verified that individuals tend to present higher levels of positive affect $(3.29 \pm 0.69)$ compared to negative affect $(1.94$ \pm 0.69 ); they also present a mean value of satisfaction with life of 26.63 \pm 5.13 . In this way, through a One-Way ANOVA analysis, and after the confirmation of data normality by a non-significant $p$ (i.e., $p \geq 0.05$ ) in a Kolmogorov-Sminorv test, it was verified that there are significant differences in every factor $(\mathrm{FAP}=3.78, \mathrm{p}=0.024$; $\mathrm{FAN}=6.24, \mathrm{p}=0.002$; $\mathrm{FSV}=5.06, \mathrm{p}=0.007$ ).
However, in the analysis of the Tukey post-hoc test, it was verified that the results show differences in the positive affect factor between individuals who belong to categories 1 and 3 ( $p=0.033$ ); in the negative affect factor between individuals who belong to categories 1 and 3 $(\mathrm{p}=0.037)$ and categories 2 and $3(\mathrm{p}=0.003)$; and lastly, in the satisfaction with life factor between individuals who belong to categories 1 and $3(\mathrm{p}=0.012)$ and categories 2 and $3(\mathrm{p}=0.036)$. Specifically, it was verified that regarding the positive affect and satisfaction with life variables, individuals from category 3 (high) present higher mean values, while in the negative affect variable, individuals from category 1 (low) present higher mean values. 


\begin{tabular}{|l|l|l|l|l|l|}
\hline & $\begin{array}{l}\text { Total Sample } \\
\text { M } \pm \text { SD }\end{array}$ & $\begin{array}{l}\text { Category 1 } \\
\text { M } \pm \text { SD }\end{array}$ & $\begin{array}{l}\text { Category 2 } \\
\text { M } \pm \text { SD }\end{array}$ & $\begin{array}{l}\text { Category 3 } \\
\text { M } \pm \text { SD }\end{array}$ & F \\
\hline N & 300 & 29 & 195 & 76 & $3.45 \pm 0.73$ \\
\hline Positive affect (PA) & $3.29 \pm 0.69$ & $3.08 \pm 0.72$ & $3.25 \pm 0.65$ & $2.01 \pm 0.70$ & $1.70 \pm 0.59$ \\
\hline Negative affect (NA) & $1.94 \pm 0.69$ & $2.07 \pm 0.78$ & $23.34 \pm 5.11$ & $25.05 \pm 4.63$ & $6.24^{* *}$ \\
\hline Satisfaction with life (SV) & $26.63 \pm 5.13$ & $21.86 \pm 5.78$ & $5.06^{* *}$ \\
\hline Note: M=Mean; SD=Standard deviation; Category 1: Low; Category 2: Moderate; Category 3: High. * $p \leq 0.05 ;{ }^{* *} p \leq 0.01$ & \\
\hline
\end{tabular}

Table 3: Means and standard deviation of subjective well-being variables and physical activity categories.

\section{Discussion}

Considering that the main goal of the present work consisted in an analysis of the impact that the goal content which lead to the practice of physical activity by older adults may have on the variables that constitute their well-being (satisfaction with life and positive and negative affect), it was verified that the initially hypothesized structural model (model 1) did not adjust itself to the data in a satisfactory manner, making it necessary to analyze the possible fragilities of the model.

After doing so, and after the correlation of the errors from the health (intrinsic) and image (extrinsic) factors, as well as the errors from the social affiliation (intrinsic) and social recognition (extrinsic) factors, the model adjusted itself to the data in a satisfactory manner. It also verified that there is a significant positive effect of the goal content related to extrinsic goal content on satisfaction with life ( $\beta .24)$ and on negative affect $(\beta .27)$. It was also verified that there is a significant and positive effect of the goal content related to the content of intrinsic objectives on positive affect ( $\beta .35$ ), a fact that corroborates the study of Sebire et al., which found positive effects of the most intrinsic objectives on individuals' well-being [10]. Regarding the analysis of the effects of the content of the objectives on the amount of physical activity, significant effects were not verified. These results confirm with the conclusions of Sebire et al. which, in a preliminary analysis, did not find correlations between the content of the objectives and physical activity behaviors [11].

Nevertheless, considering the correlation of the measurement errors mentioned in the previous paragraph, it appears that there is an indication that these factors are not perceived as different in their content (intrinsic vs. extrinsic) by the participants. This situation may have a justification from a semantic point of view, because the individuals may understand the goal content related to physical appearance as promoting objectives related to health (i.e., image may be a health factor or a representative of a healthy state). Therefore, they may have interpreted the goal content related to social affiliation as a factor of acceptance/recognition by others. However, from a conceptual point of view, this is not what is subjacent to the theoretical model of Sebire et al. because the health and social affiliation factors are associated with intrinsic content, while the image and social recognition factors are associated with extrinsic content. For this reason, we opted to analyze the individual contribution of each factor (motive) to the subjective well-being variables (satisfaction with life and positive and negative affect) [10].

In this way, it was verified that there are significant and positive effects of the health factor on satisfaction with life ( $\beta .23)$ and on positive affect ( $\beta .30)$ and of the image factor on satisfaction with life ( $\beta$. 28 ), on positive affect ( $\beta .21)$ and on negative affect ( $\beta .18)$. These effects seem to suggest that goal content related to health and image (which may have been perceived as associated in their content, as was mentioned above) make a significant contribution to the assessment individuals make of their satisfaction with life (comparison between the actual circumstances and what they define as appropriate), and are associated with the pleasurable feelings related to the presence of positive affect $[6,7,9]$. This evidence finds support in the literature, which presents health as one of the aspects that is considered to promote of high levels of quality of life and satisfaction with life $[32,33]$.

With respect to the positive effect of the image factor on negative affect, perhaps individuals who practice physical activity for reasons related to image perceive social pressure in relation to their body image, and they may not be reaching the expected results. They may then translate that fact into an increase in the experience of an aversive state of mind (a characteristic of negative affect). Markland and Ingledew concluded that a negative body image leads to less autonomous forms of motivation to exercise, which may be related to social pressure in response to determined socio-cultural patterns. In the literature, it is still possible to find evidence that dissatisfaction with image may have a substantial negative impact on different domains of the lives of older adults $[34,35]$.

Regarding the significant and positive effects of the capacity development factor on positive affect $(\beta .30)$, these may have a justification from a semantic point of view. This is because individuals may practice physical activity with the goal of developing their capacities, and consequently, may feel more excited and active, presenting a state of high energy; in other words, they may have higher levels of positive affect.

On the other hand, with regard to the justification of the effects of the social recognition factor on negative affect $(\beta .24)$, we are led to believe that individuals who practice physical activity based on goal content related to the need to be recognized by others may not reach the performance levels that allow for that recognition. They may then translate that fact into a factor that potentiates the absence of pleasurable feelings, which is characteristic of high levels of negative affectivity [7].

Another goal of this study consisted in an analysis of the differences at the subjective well-being level (satisfaction with life and positive and negative affect) according to the amount of physical activity practiced. Considering the results obtained, it seems that there is evidence that individuals with higher levels of physical activity have higher values of 
positive affect and satisfaction with life, as well as lower levels of negative affect. Consequently, high physical activity levels seem to be associated with a greater perception of subjective well-being, compared to those who have moderate physical activity levels. These results find support in the studies of Neto et al., Withall et al., Solberg et al. and Strachan et al. [17,19-21].

\section{Conclusions}

This study provides an important step in the comprehension of the role of physical activity and subjective well-being in older adults. Therefore, some effects of the goal content which lead them to practice physical activity on well-being variables (the effects of objectives' content related to health and image stand out) were identified. However, it is important to highlight that the dualistic approach to intrinsic and extrinsic goal content proved to be reductive, in that, for this type of population, there are factors that appear to be correlated (a fact that was empirically proven in our study); thus, they do not seem to be understood as differentiated from the point of view of their content (e.g., image and health).

On the other hand, the analysis of the differences in the level of subjective well-being (satisfaction with life and positive and negative affect) according to the amount of physical activity practiced verified that there seems to be a progressive effect of physical activity on the perception levels of satisfaction with life and positive affect, and respectively, the cognitive and emotional dimensions of subjective well-being.

\section{References}

1. Biddle S, Mutrie N (2001) Psychology of physical activity: Determinants, well-being and interventions (1st edn.) Routledge, Taylor \& Francis Group, London.

2. Dosil J (2008) Psicologia de la Actividad Física y del Deporte (2nd edn.). McGraw Hill, Madrid.

3. Deci E, Ryan R (1985) Intrinsic motivation and self-determination in human behavior. Plenum Press, New York.

4. Deci E, Ryan R (2008). Self-determination theory: A macrotheory of human motivation, development, and health. Can Psychol 49: 182-185.

5. Sebire SJ, Standage M, Vansteenkiste M (2008) Development and validation of the Goal Content for Exercise Questionnaire. J Sport Exerc Psychol 30: 353-377.

6. Diener E, Emmons R, Larsen R, Griffin S (1985) The satisfaction with life scale. J Pers Assess 49: 71-75.

7. Tellegen A, Watson D, Clark L (1999) On the dimensional and hierarchical structure of affect. Psychol Sci 10: 297-303.

8. Watson D, Clark L, Tellegen A (1988) Development and validation of brief measures of positive and negative affect: The PANAS scale. J Pers Soc Psychol 54: 1063-1070.

9. Pavot W, Diener E (2008) The Satisfaction with Life Scale and the emerging construct of life satisfaction. J Positive Psychol 3: 137-152.

10. Sebire S, Standage M, Vansteenkiste M (2009). Examining intrinsic versus extrinsic exercise goals: Cognitive, affective, and behavioral outcomes. J Sport Exerc Psychol 31: 189-210.

11. Sebire S, Standage M, Vansteenkiste M (2011) Predicting objectively assessed physical activity from the content and regulation of exercise goals: Evidence for a mediational model. J Sport Exerc Psychol 33: 175-197.

12. Gunnel K, Crocker P, Mack D, Wilson P, Zumbo B (2014) Goal contents, motivation, psychological need satisfaction, well-being and physical activity: A test of self-determination theory over 6 months. Psychol Sport Exer 15: 19-29.
13. Berger B, Pargman D, Weinberg R (2002) Foundations of exercise psychology. Fitness Information Technology Inc, Morgantown.

14. Buckworth J, Dishman R (2002) Exercise psychology (2nd edn.). Human Kinetics Champaign, Illinois.

15. Klusmann V, Evers A, Schwarzer R, Heuser I (2012) Views on aging and emotional benefits of physical activity: Effects of an exercise intervention in older women. Psychol Sport Exer. 13: 236-242.

16. Neto J, Lima C, Santos M, Tolentino F (2012) Bem-estar subjetivo em idosos praticantes de atividade física. Motricidade 8: 1097-1104.

17. Withall J, Stathi A, Davis M, Coulson J, Thompson J, et al. (2014) Objective indicators of physical activity and sedentary time and associations with subjective well-being in adults aged 70 and over. Int J Environ Res Public Health 11: 643-656.

18. Diener E, Chan M (2011) Happy people live longer: Subjective well-being contributes to health and longevity. Appl Psychol Health Well-Being 3: $1-43$.

19. Solberg P, Hopkins W, Ommundsen Y, Halvari H (2012) Effects of three training types on vitality among older adults: A self-determination theory perspective. Psychol Sport Exer 13: 407-417.

20. Strachan S, Brawley L, Spink K, Glazebrook K (2010) Older adults' physically-active identity: Relationships between social cognitions physical activity and satisfaction with life. Psychol Sport Exer 11: 114-121.

21. Neto F (1993). The Satisfaction With Life Scale: Psychometrics properties in an adolescent sample. J Youth Adolesc 22: 125-134.

22. Craig C, Marshall A, Sjostrom M, Bauman A, Booth M, et al. (2003). International physical activity questionnaire: 12-country reliability and validity. Med Sci Sports Exerc 35: 1381-95.

23. Hair Jr, Black W, Babin B, Anderson R (2014) Multivariate data analysis (7th ed.).Pearson Educational Inc, New Jersey .

24. Biddle S, Markland D, Gilbourne D, Chatzisarantis N, Sparkes A (2001) Quantitative and qualitative research issues in sport psychology. J Sport Sci 19: 777-809.

25. Byrne B (2010) Structural equation modeling with EQS. Basic concepts, applications, and programming (2nd ed.). Lawrence Erlbaum Associates Publishers, New Jersey, USA.

26. Worthington R, Wittaker $\mathrm{T}$ (2006) Scale development research. A content analysis and recommendations for best practices. Couns Psychol 34: 806-838.

27. Hu L, Bentler P (1999) Cut off criteria for fit indexes in covariance structure analysis: Conventional criteria versus new alternatives. Struct Equ Modeling 6: 1-55.

28. Marsh H, Hau K, Wen Z (2004) In search of golden rules: Comment on hypothesis testing approaches to setting cutoff values for fit indexes and dangers in overgeneralizing Hu and Bentler's (1999) findings. Struct Equ Modeling 11: 320-341.

29. Mardia K (1970) Measures of multivariate skewness and kurtosis. Biometrika 57: 519-530.

30. Nevitt J, Hancock GR (2001) Performance of bootstrapping approaches to model test statistics and parameter standard error estimation in structural equation modeling. Struct Equ Modeling 8: 353-377.

31. Kahn J (2006) Factor analysis in counseling psychology. Research, trainning, and practice: Principles, advances and applications. Couns Psychol 34: 684-718.

32. Paúl C, Fonseca AM, Martin I, Amado J (2005) Satisfação e qualidade de vida em idosos portugueses. In: Paúl C, Fonseca AM (eds.) Envelhecer em Portugal: Psicologia saúde e prestação de cuidados. Climepsi Editores, Lisboa pp. 77-98.

33. WHO (2010) Global recommendations on physical activity for health. World Health Organization, Geneva.

34. Markland D, Ingledew D (2007) The relationships between body mass and body image and relative autonomy for exercise among adolescent males and females. Psychol Sport Exerc 8: 836-853.

35. Matsuo R, Velardi M, Brandão M, Miranda M (2007) Imagem corporal de idosas e atividade física. Revista Mackenzie de Educação Física e Esporte 6: 37-43. 
Citation: Antunes N, Moutão J, Marinho D, Cid L (2018) Goal Content for the Practice of Physical Activity. J Aging Sci 6: 1000189. doi: 10.4172/2329-8847.1000189 